\title{
The Role of Nurses in Diabetes Care in Kuwait: A Review
}

\author{
Muna Alshammari ${ }^{*}$, Gary Adams ${ }^{2}$, Richard Windle ${ }^{2}$, Dianne Bowskill ${ }^{2}$ \\ ${ }^{1}$ College of Nursing, Kuwait; ${ }^{2}$ School of Health Sciences, Division of Nursing, Nottingham, UK
}

\begin{abstract}
The role of nurses in diabetes care in Kuwait has changed remarkably as a result of the increase of the care burden caused by the incidence of long-term diabetic patients. Nurses working in diabetes care play significant roles that are comparable to other health care providers working in diabetes clinics and centres in Kuwait.

While nurses' roles in diabetes have been clearly established in other parts of the world, nurses' role in Kuwait are neither fully recognised nor professionally acknowledged. The nurses caring for such patients do not have a special identifying title, or a clear job description that specifies their critical role in diabetes care. This review investigated the Kuwait nurses' roles in diabetes care and how the performance of their duties affects the perceived quality of the nursing care provided to their diabetic patients.

The significance of this review is that it provides an insight into the possibility of developing a new system of diabetes patient care that could result in patients accessing good quality care. By investigating patients' and nurses' perspectives, this study seeks to provide an in-depth understanding of the influence of the quality of nursing care in managing diabetic patients in Kuwait.
\end{abstract}

Keywords: Nurses; Diabetes care; Kuwait

\section{BACKGROUND}

Diabetes is becoming an increasing global public health concern with its prevalence steadily on the rise, as noted by the American Diabetes Association [1]. This growing prevalence has raised numerous calls to initiate serious steps to overcome this growth in the global number of diabetic patients. One such initiative is to empower those nurses who are involved in diabetes care so that they can take over some of the tasks currently carried out by physicians. Improved outcomes among patients with diabetes have been empirically linked to the empowerment of nurses in diabetes care [2].

Nursing care for diabetes varies across countries as a result of differences in healthcare systems and the way in which nursing is organised and practiced [3-5]. Some countries have not distinguished or categorised the role of nurses, due to inadequate empirical research; thereby failing to provide any evidence suggesting there is an urgent need to recognise the importance of nurses' roles if the quality of the services they provide are to be improved. The lack of applicable evaluation methods relating to nursing duties has led to limited evaluation of the nurses' roles for example: 'nurse consultant' [6].

This somewhat out-of-focus picture seems to describe the role of nurses in Kuwait; a picture which lacks clarity, as nurses are uncertain about their roles; a dissonance between what they are allowed to do as opposed to what they are actually able to do. This ambiguity is indicated by the lack of a published role for nurses in Kuwait, which could and perhaps should specify their function according to specialty. The absence of a well-defined role for nurses has caused lack of support in Kuwait alongside underutilisation of the nurses' roles and abilities [6]. This lack of support has been cited by some nurses as a reason for leaving the profession [7]. As Sayers et al. [8] reported in their integrative literature review of 'the nurse educator's role in acute care' there are no national or standardised approaches to the role descriptions in healthcare and therefore this current literature review must include the role performance literature.

There are some healthcare systems that are beginning to adopt nurse-led models, which are patient-centred. However, other

*Corresponding author: Muna Alshammari, PhD, MSN, BSN, College of Nursing, Kuwait, Tel: +965 2231 5961; E-mail: alshammari_pinky@msn.com

Received date: January 09, 2019; Accepted date: March 04, 2019; Published date: March 11, 2019

Citation: Alshammari M, Adams G, Windle R, Bowskill D (2019) The Role of Nurses in Diabetes Care in Kuwait: A Review. J Diabetes Metab 10:831. doi: 10.35248/2155-6156.19.10.831

Copyright: () 2019 Alshammari M, et al. This is an open-access article distributed under the terms of the Creative Commons Attribution License, which permits unrestricted use, distribution, and reproduction in any medium, provided the original author and source are credited. 
systems still keep to a more traditional physician-led model reflecting a medically oriented model of care. Managing diabetes in Kuwait involves different approaches [9] which might be a consequence of the way nursing is organised within Kuwait's healthcare system.

\section{NURSES' KNOWLEDGE AND SKILLS IN DIABETES CARE IN KUWAIT}

The role of nurses in Kuwait is not well documented [10]. Although, there are hard copies of general job descriptions for nurses at the Ministry of Health $(\mathrm{MoH})$, these roles are relatively vague as the details are not clearly presented. Presently nurses work collaboratively with other healthcare professionals to ensure that appropriate standards of care are met [11]. According to the Department of Nursing Services (DoNS) at the $\mathrm{MoH}$, the main role of nurses in Kuwait is to care for patients suffering from different diseases until those patients recover [12]. They support patients with care planning and carrying out different evaluations and procedures ordered by attending physicians, while managing the patient's recovery and assuring continuity of care. Nurses in Kuwait have also demonstrated a great deal of dedication to service provision. For instance, during the Iraqi invasion of Kuwait in 1990, nurses did not stop providing care to patients with long-term conditions, including diabetes. At that time, due to a shortage of nurses, some nurses accepted to work 24-hour shifts followed by 48-hour breaks [13], indicating their exceptionally strong commitment to caring for the sick under extremely challenging, potentially life-threatening circumstances.

In fact, the standard of nursing care in Kuwait is driven by the application of the nursing process regarding chronic care conditions; duties which include: a) assessment, b) planning, c) implementation, and $\mathrm{d}$ ) evaluating outcomes of nursing care [11]. It is important that nurses have a wide professional knowledge, even taking a role in new technologies [14]; however, there are other emerging health needs that require the involvement of nurses. For instance, it is reported that the number of patients with diabetes in Kuwait is increasing [9]. In turn such an increase causes other consequences, such as a greater use of health care services, which in turn creates a need for more strategies and resources to manage these increases.

The literature suggests that appropriately trained nurses are perceived as high-quality care providers who can maintain good health outcomes for patients [15]. There are four levels of basic nurse education in Kuwait:

- A three to four-year education programme, which follows intermediate school education (after grade 8). At this level, the student is granted a nursing diploma and the title of 'assistant nurse' after graduation;

- A two-year education programme, following high school education, whereby the student is granted an Associate Degree in Nursing (ADN) and the title of 'staff nurse';

- A four-year BSN programme, which follows high school, whereby the student is granted 'special nurse' status, and
- A post-basic programme, which comes after the diploma, whereby the student is granted a bachelor degree after graduation.

The nurses working in diabetes care in Kuwait receive training in a specialised training centre in Kuwait: the Dasman Institute. This institute works in partnership with highly qualified personnel from developed countries who provide training and education for multidisciplinary healthcare providers, including nurses [16]. From (my) personal experience, it is possible to confirm that there are nurses in Kuwait who have received training and international courses about diabetes in Egypt and the UAE, and who have received certificates as qualified diabetes educators. However, the qualifications gained by these personnel are not approved by the $\mathrm{MoH}$ in Kuwait.

In Kuwait, diabetes nursing as a specialty has not yet been established. Whilst nursing care for people with diabetes is provided by qualified nurses trained by qualified personnel from both Kuwait and abroad, these nurses are not given a grade or a title which specifies or recognises their expert role. This situation is contrary to the international vision, where titles for nurses working in diabetes care vary between countries. Examples of these titles are: a) Nurse's educator, b) Diabetes specialist nurse, and c) Diabetes nurse, based on their duty caseloads [17]. From personal experience as a nurse instructor, it is possible to conclude that nurses are able, and frequently do, demonstrate great contributions in diabetes clinics and are considered leaders in the practice of their specialties. Raja-Jones [18] conducted a literature review to identify factors relating to the role components between two groups of nurses: i) Clinical nurse specialists and ii) Clinical nurse researchers. It was found that nurses can plan and make decisions about care provision for the patients. Nurses follow particular standards of care, and are able to achieve comparable outcomes, informed by their decision-making skills, to those achieved by GPs [18]. However, the review failed to provide any useful details about the relationship between clinical and research specialist nurses in terms of role workload and role boundaries; an omission which indicates the need for further research in this area.

Nurses in Kuwait perform a significant role in collaborating with other healthcare professionals [14], which might be over and above the required role informed by the guidelines. This issue has been addressed in the literature, in that nurses are doing work that is not part of their expected, or at least guideline-specified, role $[18,19]$. These activities have not been endorsed in the literature to ensure effectiveness of nurses' contributions. Thus, nurses' roles, including their role in diabetes care, are undervalued in Kuwait as indicated by the limited support from the public and the lack of recognition about what roles nurses are playing [20]. In a qualitative study to describe the problems of recruiting and retaining student nurses in Kuwait, Al-Kandari and Ajao [21] conducted interviews with a convenience sample of 54 respondents made up of $n=25$ final year high school students, $n=20$ adults from the community and $\mathrm{n}=9$ nursing students who dropped out of their nurse education programme. A comparative analysis of the data from the three groups was used. Constant comparative analysis yielded one major societal preposition on which the recruitment and 
retention behaviours are anchored. Findings show that nursing in Kuwait is a low status and non-respected profession. The researchers concluded that this is the result of a lack of support and lack of information about the nursing profession. In order to support the role of nurses, Llahana and Hamric [22] suggested that the role of diabetes nurses needed to be well defined and clearly written, in order to precisely state the services that diabetes nurses are actually providing in diabetes care. Despite Llahana and Hamric's suggestion that an informative initiative is required, there is a significant general lack of knowledge about the nursing profession in Kuwait [21].

Furthermore, the nursing profession in Kuwait is not attractive to Kuwaiti nationals [23] as a result of the uncertainty of the role, lack of clarity about the role, and limited support from the public for the profession. The World Health Organization identified the human health resource profile in Kuwait as $11 \%$ Kuwaiti nurses and 40\% Kuwaiti doctors (WHO 2011) [24]. If the healthcare system in Kuwait seeks to achieve quality of care, in order to improve the health of patients with diabetes, then nurses with unique skills will be needed. In fact, if nurses' roles in diabetes clinics could be extended, patients might benefit [25]. An audit study was conducted to measure the quality of diabetes care in Kuwait, by reviewing the administrative structure at selected clinics in the country [26]. This structure included the diabetic nurse educator as part of the health team, who works on the provision of structured education/ treatment programmes for patients with diabetes. The study concluded that there was a need for further improvements in the quality of diabetes care that could be achieved by more structured educational programmes.

\section{QUALITY OF NURSING CARE FOR DIABETES PATIENTS IN KUWAIT}

Quality of care is considered a difficult concept to define. Donabedian [27] introduced 'quality of care' as an issue perceived from different individuals' perspectives, which made it a multidimensional concept [28]. According to the literature, there are several component dimensions of quality care including: i) Accessibility, ii) Effectiveness, iii) Efficiency [28]; iv) Continuity of care [29] and v) Patients' perspectives [30]. Campbell et al. [28] proposed a definition of quality of care for individuals as: "whether individuals can access the health structures and processes of care which they need and whether the care received is effective."

Globally, the number of patients with diabetes is increasing; a development which highlights the importance of providing high quality care for those affected [31]. Most of the literature, regardless of specification of the items of quality care, report improved patient care and better outcomes when nurses are providing a large part of this care [32-34]. In their study to examine the outcomes of assigning diabetes care from GPs to nurses in primary care, Houweling et al. [35] revealed that the majority of the patients' blood pressure, glucose, and lipid levels were well regulated. Additionally, patients in the nurse group were found to be more pleased about the method of care they received, than were the patients in the GPs group.
A key finding in the study was that patients who were allocated to the nurse group became more aware of the potential longterm complications of diabetes if their condition remained untreated [35]. This finding could indicate that nurses in the study spent more time with the diabetic patients, and made more frequent visits to them, than those assigned to the GPs. A similar finding was observed by Gabbay et al. [36] relating to the impact of nurse case management on blood pressure, HbA1C, and screening for diabetes complications, when compared to GP management. The nurse case management programme was found to achieve significant diabetes treatment goals, if and when quality nursing care was provided. Additionally, the programme developed: i) An individualised care plan, ii) Behavioural goal setting, iii) Close observation of patients, and iv) Strengthening of healthy lifestyle modifications.

Several authors have confirmed that nurses play a key role in ensuring quality in patient care $[37,38]$ as nurses can work independently to improve the general quality of care on offer [39]; factors particularly noted in the case of diabetic patients [40]. In an attempt to define the concepts of quality of care, Jackson-Frankl recruited nurses from different levels and signposted the intimate relationship between quality of care and quality of nursing care. In addition, Attree identified nurses as great contributors to the professional quality of caring for patients. Essentially, there is a need for more reliable measures regarding the concept of 'quality of nursing care', and that need seems to be difficult to deal with until there is a clear and broadly accepted definition of the concept.

The quality of nursing care depends on certain contextual and intervening conditions pertaining to the organisation involved. For instance, Irurita [41] perceived quality as being informed by personal factors affecting patients and nurses. Describing quality is unexpectedly problematic, though Attree defined it as a notion that is related to modern nursing care. Quality of nursing care includes: a) Professional skills, b) Caring behaviour and attitudes, c) Proper communication, as well as d) Effective organisational and management systems [32,42]. Quality also includes several characteristics that are informed by different roles such as nurses, physicians, and patients [27]. These various characteristics might be related to the lack of significant indicators that are used to measure the quality of nursing care. Phaneuf described quality of nursing care as a concept that is hard to measure because existing explanations about quality of nursing care are less conclusive than anticipated, and therefore no universally accepted explanation exists.

Taylor et al. [43] studied patients' and their significant others' perceptions of quality care and found that their respondents had high expectations about the issue of nursing care quality. The definitive measure about failure or success of the expected outcomes for patients is the delivery of quality nursing care [43]. Den Engelsen et al. [40] examined the effect of the introduction of practice nurses on the quality of diabetes care in the Netherlands and found that although nurses were working collaboratively with GPs, diabetes care can be transferred safely to nurses; a finding confirmed by the significant improvements in patients' conditions. In line with these studies about the introduction and identification of the quality of nursing care, 
Mitchell and Lang [44] highlighted that "within this burgeoning agenda for research, the quality of nursing care and its contribution to patient outcomes remains relatively understudied".

\section{THE ROLE OF NURSES: NURSES' PERCEPTIONS}

Although evidence regarding the significant role a nurse plays in patient care has been presented in this literature review, there is little literature about: a) Exploring the role in detail and b) How the different elements of that role contribute to the quality of nursing care $[2,45]$. Nurses might wish to provide care befitting a patient's perceptions about the quality of nursing care that is consistent with the nursing philosophy of the patient-centred model $[46,47]$. Most of the studies about nurses' perceptions of their roles have focused on: 1) Nurses' job satisfaction [19,48]; 2) Nurse retention [49]; 3) Nurse/physician relationships or substitutions [15]; 4) Nursing staffing and skill mix [50,51]; 5) Burn out [52]; 6) Role confusion [19,52] and 7) Nurses taking up more duties than was expected, as roles overlapped $[3,18]$.

\section{THE PERCEIVED AMBIGUITY OF NURSES' ROLES}

The conflict concerning nurses' roles could create fragmented care that might lead to poor patient outcomes. Nurses are performing various roles that sometimes lead to role ambiguity which, as a result, can have a negative impact on nurses' attitudes regarding their work [31]. Lu et al. [19] addressed this issue in their study on exploring nurses' perceptions regarding their working roles and found a gap between nurses expected roles and their actual roles. For instance, what nurses were actually or supposed to be doing is more than what they were actually performing. This difference can impact on a nurse's job satisfaction and create role uncertainty and conflict. Role confusion might be related to, or caused by, nurses undertaking some of the physicians' medical roles, as reported by some of the participant nurses in the study. The results indicated job dissatisfaction among $9.8 \%$ of participants with bachelor degrees. In another study, nurses with bachelor degrees were found to have high expectations in the profession. However, all the participants were females; therefore the results should be interpreted with caution and may not be applicable to other settings where both male and female nurses were participants [19].

There is no clear definition about the roles of nurses, including their advanced roles, such as their leading roles in diabetes care in New Zealand [3], or in their consultation roles in Australia [53]. Nurses in the study by Boström et al. [31] viewed their work as complex, incorporating the roles of: i) Expert, ii) Fosterer, iii) Executive, iv) Leader and v) Role model. The nurses viewed their roles as unclear and ambiguous, a conclusion which was perceived as putting them in a less powerful position in their careers. Boström et al. [31] emphasised that role ambiguity impacts negatively on patient-centred care and self-management of diabetes. In the study, the nurses' need for professional autonomy in diabetes care was obvious. The authors of the study mentioned that some nurses did not clarify their expressions about the ambiguity of their role. This might be related to the adoption of a focus group approach. Morgan [54] highlighted that the focus group approach is known to inhibit disclosure from participants who might be extremely reluctant to speak about their own concerns in the presence of others.

In summary, in Kuwait no nursing qualifications have been established beyond the level of 'registered nurse' [23]. Furthermore, the title 'diabetes nurse' has not yet been implemented, whereas the presence of nurse-led programmes in diabetes care in the UK and other countries is well-established [55]. Whilst nurses in diabetes care perform a wider range of roles within their areas of practice than general nurses do, their levels of clinical authority are the same. Physicians however, might think that nurses are doing the expected tasks in diabetes care, while what the nurses are actually performing is over and above their expected roles. The expected role of a nurse in diabetes care seems to be ambiguous, although that role is described in general and according to the nurse's hierarchical position. These documents have not been updated to include new roles for nurses, such as their role in diabetes care. Additionally, these documents are too general and insufficiently accurate, and therefore can only provide broad specifications for the different grades of nurses employed in Kuwait's hospitals and clinics.

\section{NURSES' PROFESSIONAL NEEDS}

Whilst nurses think that they are undertaking more than they should be doing in practice [3,18], Chan \& Zang [56] reported that nurses need suitable training to prepare them to provide effective diabetes care. Their study focused on nurses' perceived and actual knowledge about diabetes management, which the authors considered important for the nurses' overall performance in diabetes care. Whilst Chan \& Zang [56] confirmed the heterogeneousity of the study population, with respect to diabetes knowledge, variations of the three groups of participants were related to the lack of homogenousity of the participants' levels of training, education and experience. However, most of the participants received training in hospital settings, which resulted in good nursing skills as they received their training in natural settings [56].

\section{DISCUSSION AND CONCLUSION}

There is only limited research exploring the quality of nursing care in diabetes globally in specifically in Kuwait Previous studies reviewed nurses' and/or patients' perceptions of the quality of the nursing care that was provided $[57,58]$, but the evidence is not conclusive. A few studies compared the different nursing roles in diabetes care and identified the issue of role confusion and nurses' dissatisfaction with their roles. A number of issues were identified from the literature in the area of the role of nurses and approaches to that role in diabetes care. To date, there is a lack of studies about the role of nurses in diabetes care and the impact of this role on nurses' perceived quality of nursing care, both internationally and particularly in Kuwait. This result points to the first identified gap in the literature: no relevant study has been carried out in Kuwait that has investigated the issue of the quality of nursing care given to 
diabetic patients. Diabetes is a chronic illness and therefore requires a multidisciplinary approach in order to meet the physical, social, psychological and spiritual needs of patients and their families.

Studies have shown the various nurse-centric approaches being implemented in healthcare systems. One of the key approaches was found to hinge upon the issue of the levels of nurses' involvement, where nurses made effective contributions to diabetes care based on their qualifications, experience, knowledge and skills.

In spite of nurses' contributions in caring for diabetic patients, the literature has revealed that nurses in Kuwait, complained about their unclear roles; especially if or when nurses were implementing physicians' duties.

Finally, this paper suggests there is a need to investigate two issues highlighted by this current research. The first topic requiring investigation is the lack professional recognition and public respect for members of the nursing profession in Kuwait, indicated by negative public opinion. This atypical low status vision of nursing is relatively unusual from a global perspective so there is a need to improve this status in Kuwait by establishing strategies for enhancing and publicizing nurses' professional contributions in different areas of medical specialization, including diabetes management for long term patients. The question "what are the causes of this lack of recognition of the professional roles played by nurses in Kuwait?" needs to be both posed and answered.

The second issue addressed in this paper is the need to create a diabetes nurse specialist role in Kuwait, informed by the initiatives of other nations that have already implemented this special role. Nurses elsewhere are, in fact, delivering what the author of this paper is after, but this helpful and much needed initiative is yet to appear in Kuwait. An investigation into the roles and expectations informing Kuwait's nursing workforce is called for as a matter of some urgency, with a particular orientation towards the issue of diabetes management.

\section{REFERENCES}

1. American Diabetes Association. Statistics about diabetes. 2014;7:14.

2. Juul L, Maindal HT, Frydenberg M, Kristensen JK, Sandbaek A. Quality of type 2 diabetes management in general practice is associated with involvement of general practice nurses. Prim Care Diabetes. 2012;6:221-228.

3. Daly B, Arroll B, Sheridan N, Kenealy T, Scragg R. Characteristics of nurses providing diabetes community and outpatient care in Auckland. J Prim Health Care. 2013;5:19-27.

4. Aiken LH, Sloane D, Bruyneel L, Van den Heede K, Griffiths P, Busse R, et al. Nurse staffing and education and hospital mortality in nine European countries: a retrospective obsrvational study. Lancet 2014;383:1824-1830.

5. Cho SH, Kim YS, Yeon KN, You SJ, Lee ID. Effects of increasing nurse staffing on missed nursing care. Int Nurs Rev. 2015;62:267-274.

6. Bloomer MJ, Cross WM. An exploration of the role and scope of the clinical nurse consultant (CNC) in a metropolitan health service. Collegian. 2011;18:61-69.
7. Flinkman M, Leino-Kilpi H, Sanna S. Nurses' intention to leave the profession: integrative review. J Adv Nurs. 2010;66:1422-1434.

8. Sayers J, Digiacomo M, Davidson PM. The nurse educator role in the acute care setting in Australia: important but poorly described. Aust J Adv Nurs. 2011;28:44-52.

9. Al-Adsani A, Moussa M, Al-Jasem L, Abdella N, Al-Hamad N. The level and determinants of diabetes knowledge in Kuwaiti adults with type 2 diabetes. Diabetes Metab. 2009;35:121-128.

10. AlKandari F, Thomas D. Factors contributing to nursing task incompletion as perceived by nurses working in Kuwait general hospitals. J Clin Nurs. 2009;18:3430-3440.

11. Al-Kandari F, Ogundeyin W. Patients' and nurses' perceptions of the quality of nursing care in Kuwait. J Adv Nurs. 1998;27:914-921.

12. Al-Mailam FF. The effect of nursing care on overall patient satisfaction and its predictive value on return-to-provider behavior: a survery study. Qual Manag Health Care. 2005;14:116-120.

13. Baggs AC. Kuwaiti physcians, hospitals witnessed atrocities before, after liberation. CMAJ. 1991;144:1500.

14. Al-Jarallah KF, Moussa MA, Hakeem SK, Al-Khanfar FK. The nursing workforce in Kuwait to the year 2020. Int Nurs Rev. 2009;56:65-72.

15. Laurent M, Reeves D, Hermens R, Braspenning J, Grol R, Sibbald $B$, et al. Substitution of doctors by nurses in primary care. Cochrane Database Syst Rev. 2005;18:CD001271.

16. Behbehani K. Kuwait National Programme for healthy living: first 5-year plan (2013-2017). Med Princ Pract. 2014;33:32-42.

17. Funnell MM, Brown TL, Childs BP, Haas LB, Hosey GM, et al. National standards for diabetes self-management education. Diabetes care. 2009;32:S87-S94.

18. Raja-Jones HA. Role boundaries- research nurse or clinical nurse specialist? A literature review. J Clin Nurs. 2002;11:415-420.

19. Lu H, While A, Barriball K. Job satisfaction and its realted factors: A questionnaire survey of hospital nurses in Mainland China. Int J Nurs Stud. 2007;44:574-588.

20. Al-Enezi N, Chowdhury RI, Shah MA, Al-Otaibi M. Job satisfaction of nurses with multicultural backgrounds: a questionnaire survey in Kuwait. Appl Nurs Res. 2009;22:94-100.

21. Al-Kandari FH, Ajao E. Recruitment and retention of nursing students in Kuwait. Int J Nurs Stud. 1998;35:245-251.

22. Llahana S, Hamric A. Developmental phases and factors influencing role development in diabetes specialist nurses: a UK study. EDN. 2001;8:18.

23. Al-Kandari F, Thomas D. Adverse nurse outcomes: correlation to nurses' workload, staffing, and shift rotation in Kuwaiti hospitals. Appl Nurs Res. 2008;21:139-146.

24. World Health Organisation. Health System Profile: Kuwait (EMRO) Regional Health Systems Observatory. 2014.

25. Vrijhoef H, Diederiks J, Spreeuwenberg C, Wolffenbuttel B, Van Wilderen $\mathrm{L}$. The nurse specialist as main care-provider for patients with type 2 diabetes in a primary care setting: effects on patient outcomes. Int J Nurs Stud. 2002;39:441-451.

26. Al-Adsani A, Al-Faraj J, Al-Sultan F, El-Feky M, Al-Mezel N, Saba $\mathrm{W}$, et al. Evaluation of the impact of the Kuwait Diabetes Care Program on the quality of diabetes care. Med Princ Pract. 2008; 17:14-19.

27. Donabedian A. Quality of care: problems of measurement. II. Some issues in evaluating the quality of nursing care. Am J Public Health Nations Health. 1969;59:1833-1836.

28. Campbell SM, Ronald MO, Buetow SA. Defining quality of care. Soc Sci Med. 2000;51:1611-1625. 
29. Van Servellen G, Fongwa M, Mockus D'Errico E. Continuity of care and quality care outcomes for people experiencing chronic conditions: A literature review. Nurs Health Sci. 2006;8:185-195.

30. Lu S, Harris MF. Prevention of diabetes and heart disease patient perceptions on risk, risk assessment and the role of their GP in preventive care. Aust Fam Physician. 2013;42:328-331.

31. Boström E, Isaksson U, Lundman B, Sjölander AE, Hörnsten $\AA$. Diabetes specialist nurses' perceptions of their multifaceted role. EDN. 2012;9:39-44.

32. Mrayyan M. Jordanian nurses' job satisfaction, patients' satisfaction and quality of nursing care. Int Nurs Rev. 2006;53:224-230.

33. Irvine Doran D, O'brien-Pallas L, Sidani S, Mcgillis Hall L, Petryshen P, Hawkins J, et al. The relationship between patient and system outcomes and the quality of nursing care in acute care hospitals. Final Report. 2001;660606564-001

34. Aiken LH, Clarke SP, Sloane DM. Hospital staffing, organization, and quality of care: cross-national findings. Nurs Outlook. 2002;50:187-194.

35. Houweling ST, Kleefstra N, Van Hateren KJJ, Groenier KH, Meyboom-De Jong B, Bilo HJ, et al. Can diabetes management be safely transferred to practice nurses in a primary care setting? A randomised controlled trial. J Clin Nurs. 2011;20:1264-1272.

36. Gabbay RA, Lendel I, Saleem TM, Shaeffer G, Adelman AM, Mauger DT, et al. Nurse case management improves blood pressure, emotional distress and diabetes complication screening. Diabetes Res Clin Pract. 2006;71:28-35.

37. Bodenheimer T, MacGregor, Stothart N. Nurses as leaders in chronic care. BMJ. 2005;330:612-613.

38. Zhao, SH, Akkadechanunt T, Xue XL. Quality nursing care as perceived by nurses and patients in a Chinese hospital. J Clin Nurs. 2009; 18:1722-1728.

39. Horrocks S, Anderson E, Salisbury C. Systematic review of whether nurse practitioners working in primary care can provide equivalent care to doctors. BMJ. 2002;324:819-823.

40. Den Engelsen C, Soedamah-Muthu SS, Oosterheert NJ, Ballieux MJ, Rutten GE. Improved care of type 2 diabetes patients as a result of the introduction of a practice nurse: 2003-2007. Prim Care Diabetes. 2009;3:165-171.

41. Irurita VF. Factors affecting the quality of nursing care: the patient's perspective. Int J Nurs Pract. 1999;5:86-94.

42. Redfern S, Norman I. Quality of nursing care perceived by patients and their nurses: an application of the critical incident technique. Part 2. J Clin Nurs. 1999;8:414-421.

43. Taylor S, White B, Muncer S. Nurses' cognitive structural models of work-based stress. J Adv Nursing. 1999;29:974-983.
44. Mitchell PH, Lang NM. Framing the problem of measuring and improving healthcare quality: has the Quality Health Outcomes Model been useful? Med Care. 2004;42:11-14.

45. Bergman K, Perhed U, Eriksson I, Lindblad U, Fagerstrom L. Patients' satisfaction with the care offered by advaneced practice nurses: A new role in Swedish primary care. Int J Nurs Pract. 2013;19:326-333.

46. McCabe C. Nurse-patient communication: an exploration of patients' experiences. J Clin Nurs. 2004;13:41-49.

47. McCormack B, McCane TV. Development of a framework for person-centred nursing. J Adv Nurs. 2006;56:472-479.

48. Spence Laschinger HK, Finegan J, Shamian J. The impact of workplace empowerment, organizational trust on staff nurses' work satisfaction and organizational commitment. Adv Health Care Man. 2002;3:59-85.

49. Jones $\mathrm{CB}$, Gates $\mathrm{M}$. The costs and benefits of nurse turnover: $\mathrm{A}$ business case for nurse retention. OJIN. 2007;12:3.

50. Aiken LH, Clarke SP, Sloane DM, Sochalski JA, Busse R, Clarke $\mathrm{H}$, et al. Nurses' reports on hospital care in five countries. Health Aff (Millwood). 2001;20:43-53.

51. Currie V, Harvey G, West E, McKenna H, Keeney S. Relationship between quality of care, staffing levels skill mix and nurse autonomy: literature review. J Adv Nurs. 2005;51:73-82.

52. Piko BF. Burnout, role conflict, job satisfaction and psychosocial health among Hungarian health care staff: A questionnaire survey. Int J Nurs Stud. 2006;43:311-318.

53. Baldwin R, Duffield CM, Fry M, Roche M, Stasa H, Solman A, et al. The role and functions of Clinical Nurse Consultants, an Australian advanced practice role: A descriptive exploratory cohort study. Int J Nurs Stud. 2013;50:326-334.

54. Morgan D, Kreuger RA. When to use focus groups and why. Successful focus groups: Advancing the state of the art. 1993; 1:3-19.

55. Carey N, Courtenay M. A review of the activity and effects of nurseled care in diabetes. J Clin Nurs. 2007;16:296-304.

56. Chan MF, Zang YL. Nurses' perceived and actual level of diabetes mellitus knowledge: results of a cluster analysis. J Clin Nurs. 2007; 16:234-242

57. Williams RP. Nurse leaders' perceptions of quality nursing: An analysis from academe. Nurs Outlook. 1998;46:262-267.

58. Lee MA, Yom YH. A comparative study of patients' and nurses' perecptions of the quality of nursing services, satisfaction and intent to revisit the hospital: A questionnaire survey. Int J Nurs Stud. 2007;44:545-555. 